\title{
La Cooperacion: iun Instrumento de Refuerzo del Soft Power?
}

\author{
Cooperation: is it an Instrument \\ of the Reinforcement of the Soft Power?
}

Recibido: Enero 2008

\section{Resumen:}

El concepto de la existencia de Soft Power (Poder Blando) desarrollado por Joseph Nye, y que se basa en los recursos que profundizan el poder de un Estado, puede identificarse hoy en otros actores de la escena internacional como las organizaciones internacionales. Las dinámicas de cooperación internacional, al interior de dichas organizaciones, parecen acompañar la existencia de este tipo de poder. Es así como el fenómeno de la francofonía ha revelado ser un terreno rico para el estudio de un modelo de Soft Power que se ejerce a nivel institucional, en el seno de organismos como la Organización Internacional de la Francofonía - OIF y en relación con la Organización de la Naciones Unidas - ONU y sus operadores como la UNESCO; y a nivel bilateral entre Estados por ejemplo en la relación de cooperación bilateral entre Francia y Colombia. A fin de verificar esta afirmación, esta investigación muestra una lectura tanto cuantitativa como cualitativa de las acciones que evidencian la existencia de dicho tipo de poder se revela indispensable.

\section{Palabras Claves:}

Soft power, organización internacional, poder, francofonía, cooperación bilateral.

\section{Abstract:}

The concept of the existence of the Soft Power, developed by Joseph Nye, and which is based upon the resources that deepen the power of a State, may be identified today with other actors of the international scenario and the international organizations. The dynamics of the international cooperation, within these organizations, seem to accompany the existence of this type of power. And it is in this way that the phenomenon of the Francophonie has turned out to be a breeding ground for the study of a model of Soft Power which is exerted in the institutional level within organizations like the International Organization of la Francophonie - OIF - and in relation to the United Nations Organizations UNO - and its operators like UNESCO, and in the bilateral level between States, for example, in the relationship of bilateral cooperation between France and Colombia. In order to verify such a statement, this research shows both a quantitative and qualitative reading of the actions which make evident the existence of such a type of power which turns out to be essential.

\section{Key words:}

Soft Power, international cooperation, power, Francophonie, bilateral cooperation. 


\section{Metodologia}

Este artículo busca verificar la veracidad del postulado que supone que la cooperación internacional podría ser un instrumento para la profundización del Soft Power (Poder Blando)', entre los actores de la escena internacional actual. Para dicha verificación hemos elegido utilizar el campo ${ }^{2}$ de la francofonía institucional y no institucional. Este estudio está elaborado o sustentado desde un punto de vista que pone en perspectiva una investigación universitaria realizada una joven investigadora en Ciencia Política y de la experiencia profesional de veinticinco años de un agente francés de cooperación bilateral quien ejerció sus funciones en la Embajada de Francia ${ }^{3}$, específicamente. Este artículo sienta sus bases sobre un doble soporte: por un lado, moviliza ciertos conceptos propios al Soft Power. Por el otro lado, versa sobre aspectos específicos a la cooperación: acciones institucionales, cooperación bilateral y multilateral

En este orden de ideas, nuestro objetivo será igualmente doble. Por una parte se interrogará el concepto de Soft Power imaginado por Joseph $\mathrm{NYE}^{4}$ y su existencia en el seno de las relaciones internacionales y de la cooperación, por otra parte, se intentará ver cómo, en el caso específico de la francofonía, este poder se refuerza mediante las acciones de cooperación internacional de esquema Norte-Sur que tienen lugar desde los miembros de la Organización Internacional de la Francofonía (OIF) $)^{5}$ hacia los países en desarrollo.

Como observación preliminar llamamos la atención del lector sobre las dos vertientes de la francofonía. La primera se califica de institucional y se escribe con " $F$ " mayúscula. Ella se configura a partir de organismos nacionales e internacionales como los Servicios de Cooperación del Ministerio Francés de Asuntos Exteriores y Europeos', universidades del Quebec, francesas y belgas, o transnacionales como la Organización Internacional de la Francofonía (OIF), la Agencia Universitaria de la Francofonía (AUF) ${ }^{7}$, la Alianza Francesa, la Unión Latina. La segunda es aquella de la francofonía escrita con " $f$ " minúscula. Esta tiene que

aDoctor de la Sorbona - Paris III. Agregado de Cooperación para el francés, Servicio de Cooperación y de Acción Cultural Embajada de Francia en Colombia 2001 -2005. Actualmente: Funcionario del Estado francés. Agente de la Red de Servicios de Cooperación y de Acción Cultural de Francia en diferentes países entre los que se cuentan Turquía, República Dominicana, Mozambique, Colombia, durante veinticinco años. Ex - Maître de Confèrences Responsable de Relaciones Internacionales para el Departamento de Estudios Pluridisciplinarios Aplicados (DEPA). Universidad de las Antillas y de la Guyana. jacquesleylavergne@hotmail.com

${ }^{b}$ Magister en Análisis de Problemas Políticos, Económicos e Internacionales Contemporáneos - Universidad Externado de Colombia - Instituto de Altos Estudios para el Desarrollo - Sorbonne Paris III. Actualmente: Profesora Universidad San Buenaventura de Cartagena. parra_andrea@yahoo.fr 
ver con un concepto multiforme que consiste en un sentimiento de pertenencia informal, que a menudo no reposa sobre relación material alguna con la lengua y la cultura y que tiene que ver más bien con una representación afectiva, heredada en ocasiones de una tradición familiar o social.

Así, en la primera parte de este artículo delimitaremos el concepto de Soft Power, en la segunda parte, expondremos el resultado de una investigación, cuyo objetivo fue establecer la existencia del Soft Power dentro de la Organización Internacional de Francofonía que para fines de este artículo y a fin de facilitar la lectura será denominado OIF. Dicho investigación tuvo como marco referencial las votaciones en la Asamblea General de las Naciones Unidas en los períodos correspondientes a sus sesiones número $59^{\circ}, 60^{\circ}$ y $61^{\circ}$ y que tuvieron lugar entre octubre del 2004 y septiembre del $2007^{8}$. Adicionalmente, hemos de interrogarnos acerca del papel que juega la OIF como organismo de cooperación y sus ejes principales.

Para terminar, en una tercera parte intentaremos demostrar el verdadero impacto de la cooperación bilateral a través de un caso específico: la cooperación bilateral Francia-Colombia y el Soft Power que ella infiere en el campo de la francofonía.

\section{Introducción}

\subsection{El "Soft Power", un concepto en devenir.}

En la dinámica de la escena internacional actual, el tema del poder se ha revestido de importancia renovada. Esto tiene sus orígenes en una reconfiguración del concepto planteada en Foreign Policy en el año de 1990, por el teórico de las relaciones internacionales Joseph NYE. Desde su perspectiva, el poder se articula a partir de en una configuración tridimensional $^{10}$. De ella hacen parte Hard power, Poder Económico y Soft Power ${ }^{11}$. A fin de entender el aspecto innovador del concepto hemos de dar una mirada conceptual a la definición de poder en su sentido más general:

Max WEBER define poder como "(...) toda oportunidad de hacer triunfar, en el seno de una relación social, su propia voluntad, incluso contra las resistencias, sin importar sobre qué repose dicha oportunidad"12. Poder sería entonces la habilidad de alterar el comportamiento de otros para obtener lo que se quiere ${ }^{13} \sin$ importar los medios. Y son los medios los que en la versión del término propuesta por NYE, ubican el concepto sobre un "ajedrez tridimensional"14. Esta imagen de ajedrez tridimensional implica una distribución del poder en tres tableros imaginarios. Según palabras de NYE "En el tablero superior, el poder militar es generalmente unipolar... pero en el tablero del centro el poder económico es multipolar... El tablero inferior es el reino de las relaciones trasnacionales, que rebasan las fronteras quedando fuera del control gubernamental ${ }^{\prime \prime 15}$. En otras palabras, para este autor, se ejerce poder imponiéndose por medio de coerción militar por un lado, induciendo comportamientos (mediante presiones económicas) 
por otro, ó generando cooptación y atracción que implica identificación con valores, identidades ${ }^{16}$...

Es de este modo que Soft Power hoy es entendido como la capacidad de obtener lo que uno desea, atrayendo a los demás en lugar de amenazarlos o pagarles ${ }^{17}$. De hecho, poder blando designa la capacidad para un actor " $A$ " de influir en un actor " $B$ " para que éste adopte el punto de vista del actor " $A$ " por la vía de medios culturales y/o ideológicos. ${ }^{18}$ Dicho concepto conlleva recursos basados en el atractivo y la seducción encarnados por el modelo cultural del actor " $\mathrm{A}^{\prime \prime 19}$. Se trata de un poder que se basa en el atractivo que se puede ejercer a partir de la cultura y su imagen, de los valores políticos que se comparten y en la política exterior ${ }^{20}$ que se define por la forma en la que se actúa en el contexto internacional. De hecho se entiende que cuanto más amplios sean los valores que un actor defiende y de los que hace su estandarte, mucho mayor será la influencia que tendrá frente a los otros. Esto se da no sólo en términos de profundidad de la influencia cultural que se ejerce sino también en términos de la cantidad de países que conseguiría influir por diferentes intereses ${ }^{21}$

Al respecto es interesante constatar que la noción de poder blando se ha convertido en un concepto dinámico que además, ha evolucionado en dieciocho años. NYE, hoy define como uno de los factores del poder blando "... la capacidad de organizar la agenda política de forma que configure las preferencias de otros" ${ }^{\prime \prime 2}$ porque "la universalidad de la cultura de un país y su capacidad para establecer una serie de normas e instituciones favorables que gobiernen áreas de actividad internacional son importantes resortes de poder... ". ${ }^{23}$ El poder ya no es algo que simplemente se ejerce porque se poseen ciertos recursos. Es algo que pasa por moldeo de las políticas exteriores de los actores implicados a fin de cooptar adeptos. Recordemos que mediante el Soft Power, el atractivo de un actor internacional incrementa su presencia en el escenario internacional; lo hace más influyente.

Es cierto que esta teoría se basa en una lectura hecha por Joseph NYE del poder de los Estados Unidos, de su influencia y sus alcances. Pero por qué no preguntarnos si 己̇el mismo tipo de poder no puede ser encontrado en otros actores internacionales que no sean Estados? ¿̇Acaso actores como ciertas Organizaciones Internacionales dedicadas al fomento de la cultura no pueden ejercer igulamente Soft Power en la escena internacional? Parece que sí.

Si se parte del postulado que el poder que se refuerza mediante acciones de tipo cultural y valores universalmente compartidos se denomina Soft Power. Si al igual se observa que existen organizaciones internacionales cuya vocación primordial es justamente la defensa de valores universales como la libertad, la democracia, la igualdad...; entonces se puede hablar de Soft Power de las Organizaciones Internacionales. 
Organizaciones de vocación netamente cultural y (desde hace algunos años) política, como la Organización Internacional de la Francofonía - OIF (organización internacional cuya sede central está en París y que agrupa a Estados que tienen en la francofonía su nexo de unión cultural), parecen ejercer un Soft Power idéntico al que se puede identificar en los Estados. Por ejemplo, el hecho de vehiculizar una imagen de prosperidad, de interés profundo en el desarrollo, son recursos de este tipo de poder en su interior. De hecho, la naturaleza misma de Organización Internacional se eleva a la condición de elemento constitutivo de su poder. Como diría NYE en su libro La paradoja del Poder Norteamericano, "(M) muchas de ellas afirman servir como "conciencia global", representando amplios intereses públicos más allá del alcance de los intereses individuales, o intereses que los Estados son proclives a ignorar. Las organizaciones no gubernamentales desarrollan normas nuevas directamente, presionando a los gobiernos y a los empresarios para que cambien sus medidas políticas e indirectamente alterando la percepción pública respecto a lo que los gobiernos y las empresas deberían estar haciendo... la revolución de la informática ha incrementado enormemente su poder blando... ${ }^{24 " ~}$ La facultad de cohesionar los intereses de los Estados miembros en torno a dicha conciencia global, es en sí misma, una manifestación de Soft Power.

Ahora bien, la paradoja del poder radica en que su propia existencia lo alimenta. Cuanto más, Organizaciones como la OIF se establecen en consciencias globales, mayor es su credibilidad (otra de las fuentes del Soft Power ${ }^{25}$ ), mayor es el alcance de su poder. Es un poder que viaja por todas partes del planeta, que viaja en las mentes de los adeptos que han sucumbido al atractivo de la cultura que la Organización vehiculiza. Retomando a NYE "la cultura se transmite por varias vías: (...) el comercio es sólo una de ellas. Esto también tiene lugar mediante contactos personales, visitas e intercambios. Las ideas y los valores que los Estados Unidos exportan en las mentes de más de medio millón de estudiantes universitarios extranjeros... o empresarios asiáticos... tiende a alcanzar las élites con su poder. ${ }^{26}$ La OIF, mediante cooperación entre sus Estados miembros y con otras organizaciones como la UNESCO o la ONU y mediante la defensa activa de la democracia y el desarrollo sostenible, también exporta sus ideales y forma sus élites de poder.

Surge a partir de esta reflexión, la necesidad de verificar cuantitativamente este postulado. Es así como en esta segunda parte, expondremos el resultado de una investigación llevada a cabo en 2007, que buscaba verificar la evidencia del Soft Power de la OIF en el seno de la Organización de las Naciones Unidas.

\section{Resultados.}

Para fines de este artículo, la reflexión parte del postulado siguiente: de haber Soft Power, éste puede ser ejercido por la organización de dos maneras. 
La primera, mediante su peso numérico. Dicho peso permitiría a la OlF tender a actuar como un grupo de presión, teniendo en cuenta que la agrupación de estos países representa aproximadamente un tercio de la totalidad de los Estados miembros de la ONU (65 de 192). Es un agrupamiento deseado por Francia y pasa por el refuerzo y la colaboración de esos países que comparten el francés como su lengua. Una voluntad tal lleva un nombre: aquel de voluntad política. Nosotros vemos allí las premisas de una tentación de Soft Power y żdónde puede ejercerse éste de la manera más eficaz posible sino en el seno de los grandes organismos internacionales como la ONU?

La segunda, tiene lugar mediante la cooperación. Siendo la OIF igualmente una organización con fines de cooperación, el Soft Power podría también verse reforzado por las diferentes acciones en este campo.

A fin de clarificar nuestro postulado, distinguiremos claramente nuestra primera hipótesis de la segunda. En efecto, si la primera releva de la práctica multilateral en política internacional, la segunda es totalmente identificable como cooperación desde un eje Norte-Sur. Por esta razón, intentaremos primero, rendir cuenta de un estudio dicha práctica y en la segunda, daremos un recorrido por las acciones de cooperación de la Organización.

Para iniciar presentaremos algunas observaciones preliminares. Nuestra aproximación de la problemática debía apoyarse sobre la hipótesis que los Estados miembros de la OIF ejercen, reuniéndose en una sola fuerza política, un Soft Power. Éste se manifestaría con ocasión de la votación de las Resoluciones propuestas en la Asamblea General de las Naciones Unidas a sus 192 Estados miembros. Naturalmente, ésta hipótesis, para ser confirmada o negada, nos conduce a una aproximación sincrónica y luego diacrónica de los votos. En efecto, una reflexión acerca de la única actualidad presente (o de un pasado reciente) sólo habría dado cuenta de una situación dada en un momento dado. Siendo ésta demasiado restrictiva, nos pareció necesario hacer un estudio en el tiempo, eligiendo, además de la sesión $61^{\text {a }}$ correspondiente al período $2006-2007^{27}$, las dos sesiones anteriores $\left(60^{a 28}\right.$ y $\left.59^{a 29}\right)$. Lo anterior buscaba poner en evidencia una evolución en el comportamiento de voto de los países miembros de la OlF y en sus dinámicas de adopción de una u otra Resolución. Notemos que nuestra elección de observar el resultado de dichas votaciones estuvo condicionada por el hecho que las Resoluciones, adoptadas o no, no debían haberlo sido de manera unánime. Así, para poder analizar los principios que influyeron la votación de las Resoluciones en cuestión, era necesario que los votos llamaran la atención, que fueran divergentes.

Es de esta manera como quince Resoluciones, distribuidas en los tres períodos, se eligieron para el presente análisis. Éste se efectuó en dos momentos. El primero fue un ejercicio, que puramente empírico, buscaba total objetividad y se apoyaba únicamente sobre cifras y estadísticas. Se 
buscaba aquí comparar los votos de los Estados pertenecientes a la OIF y aquellos de los Estados miembros de la ONU. Cada una de dichas Resoluciones sería además objeto de un estudio riguroso del comportamiento de voto de los Estados miembros de la OIF representados en la ONU.

El segundo, tomaba en cuenta, por el contrario, el contenido de cada Resolución y se desarrolló en una dirección interpretativa más extensa. Sin embargo, las proposiciones que se avanzaron fueron extremadamente prudentes. Habría sido, en efecto, una gran tentación llegar a conclusiones guiadas únicamente por la intuición o por una visión parcial de la problemática.

A fin de hacer legible nuestra reflexión llamaremos grupo Francia, a aquel compuesto por los países de la OIF que han votado en la misma dirección que este. En ningún caso, se trata de proponer de entrada una clasificación arbitraria, se trata simplemente de hacer una lectura del comportamiento de voto de los miembros de la OIF para cada una de dichas Resoluciones.

\subsection{Votos del 61 período de sesiones}

El cuadro 1, representa las Resoluciones votadas durante el 610 período de Sesiones de la Asamblea General de las Naciones Unidas. Como en los otros dos cuadros presentados a continuación se pondrá en perspectiva (como fue anunciado anteriormente), la votación de los miembros de la $\mathrm{OIF}^{30}$ y aquellos de los miembros de la ONU.

Para el estudio del $61^{\circ}$ periodo de sesiones (2006/2007) las resoluciones elegidas fueron: A/RES/61/170, A/RES/61/166, A/RES/61/159, A/RES/61/156, A/RES/61/151.

\section{Cuadro 1: $61^{\circ}$ periodo de sesiones (septiembre de 2006 a septiembre de 2007)}

\begin{tabular}{|c|c|c|c|c|c|c|c|c|c|c|c|}
\hline \multirow[b]{2}{*}{$\begin{array}{l}\text { RESOLUCI } \\
\text { ONES }\end{array}$} & \multirow[b]{2}{*}{$\begin{array}{l}\text { TITULO DE LA } \\
\text { RESOLUCION }\end{array}$} & \multicolumn{5}{|c|}{65 Estados de la Francofonía } & \multicolumn{5}{|c|}{192 Estados de I'ONU } \\
\hline & & $\begin{array}{l}\text { Voto } \\
\text { sy } \\
\%\end{array}$ & $\begin{array}{l}\text { A } \\
\text { favor }\end{array}$ & $\begin{array}{l}\text { En } \\
\text { contr } \\
\text { a }\end{array}$ & $\begin{array}{l}\text { Abste } \\
\text { nción }\end{array}$ & $\begin{array}{l}\text { Ausen } \\
\text { tes }\end{array}$ & $\begin{array}{l}\text { Votos } \\
\text { y } \%\end{array}$ & $\begin{array}{l}\text { A } \\
\text { favor }\end{array}$ & $\begin{array}{l}\text { En } \\
\text { contr } \\
\text { a }\end{array}$ & $\begin{array}{l}\text { Abste } \\
\text { nción }\end{array}$ & $\begin{array}{l}\text { Aus } \\
\text { ent } \\
\text { es }\end{array}$ \\
\hline \multirow[t]{2}{*}{$\begin{array}{l}\text { A/RES/61 } \\
/ 170\end{array}$} & \multirow{2}{*}{$\begin{array}{l}\text { "Derechos } \\
\text { humanos y } \\
\text { medidas } \\
\text { coercitivas } \\
\text { unilaterales". }\end{array}$} & \#V & 38 & $\begin{array}{l}23 \\
\text { Franc } \\
\text { ia }\end{array}$ & 0 & 4 & $\# \mathbf{V}$ & 131 & 54 & 0 & 7 \\
\hline & & $\%$ & $\begin{array}{l}\mathbf{5 8 , 5} \\
\%\end{array}$ & $\begin{array}{l}35,5 \\
\%\end{array}$ & $0 \%$ & $6 \%$ & $\%$ & $68 \%$ & $28 \%$ & $0 \%$ & $4 \%$ \\
\hline \multirow[t]{2}{*}{$\begin{array}{l}\text { A/RES/61 } \\
/ 166\end{array}$} & \multirow{2}{*}{$\begin{array}{l}\text { "Promoción de } \\
\text { un dialogo en } \\
\text { materia de } \\
\text { derechos } \\
\text { humanos } \\
\text { basado en la } \\
\text { equidad y el } \\
\text { respeto mutuos". }\end{array}$} & $\# \mathbf{v}$ & 27 & $\begin{array}{l}24 \\
\text { Franc } \\
\text { ia }\end{array}$ & 7 & 7 & 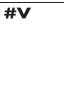 & 86 & 64 & 26 & 16 \\
\hline & & $\%$ & $42 \%$ & $37 \%$ & $10,5 \%$ & $10,5 \%$ & $\%$ & $45 \%$ & $\mathbf{3 3} \%$ & $13 \%$ & $9 \%$ \\
\hline \multirow{2}{*}{$\begin{array}{l}\text { A/RES/61 } \\
/ 159\end{array}$} & \multirow{2}{*}{$\begin{array}{l}\text { "Composición } \\
\text { del personal de } \\
\text { la oficina del } \\
\text { alto comisionado } \\
\text { de las Naciones } \\
\text { Unidas para los } \\
\text { derechos } \\
\text { humanos". }\end{array}$} & \#V & 34 & 1 & $\begin{array}{l}25 \\
\text { Franci } \\
\text { a }\end{array}$ & 5 & $\# \mathbf{V}$ & 118 & 7 & 55 & 12 \\
\hline & & $\%$ & $\begin{array}{l}\mathbf{5 2 , 5} \\
\%\end{array}$ & $1,5 \%$ & $38,5 \%$ & $7,5 \%$ & $\%$ & $\begin{array}{l}61,5 \\
\%\end{array}$ & $3,5 \%$ & $29 \%$ & $6 \%$ \\
\hline
\end{tabular}




\begin{tabular}{|c|c|c|c|c|c|c|c|c|c|c|c|}
\hline \multirow[t]{2}{*}{$\begin{array}{l}\text { A/RES/61 } \\
/ 156\end{array}$} & \multirow{2}{*}{$\begin{array}{l}\text { "la globalización } \\
\text { y sus } \\
\text { consecuencias } \\
\text { para el pleno } \\
\text { disfrute de todos } \\
\text { los derechos } \\
\text { humanos". }\end{array}$} & $\# \mathbf{V}$ & 37 & $\begin{array}{l}25 \\
\text { Franc } \\
\text { ia }\end{array}$ & 0 & 3 & \#V & 130 & 54 & 3 & 5 \\
\hline & & $\%$ & $57 \%$ & $\begin{array}{l}38,5 \\
\%\end{array}$ & $0 \%$ & $4,5 \%$ & $\%$ & $68 \%$ & $28 \%$ & $1,5 \%$ & $\begin{array}{l}2,5 \\
\%\end{array}$ \\
\hline \multirow{2}{*}{$\begin{array}{l}\text { A/RES/61 } \\
/ 151\end{array}$} & \multirow{2}{*}{$\begin{array}{l}\text { "Utilización de } \\
\text { mercenarios } \\
\text { como medio de } \\
\text { violar los } \\
\text { derechos } \\
\text { humanos y } \\
\text { obstaculizar el } \\
\text { ejercicio del } \\
\text { derecho de los } \\
\text { pueblos a la } \\
\text { libre } \\
\text { determinación". }\end{array}$} & $\# \mathbf{V}$ & 37 & $\begin{array}{l}23 \\
\text { Franc } \\
\text { ia }\end{array}$ & 2 & 3 & \#V & 127 & 51 & 7 & 7 \\
\hline & & $\%$ & $57 \%$ & $\begin{array}{l}35,5 \\
\%\end{array}$ & $3 \%$ & $4,5 \%$ & $\%$ & $\begin{array}{l}66,5 \\
\%\end{array}$ & $\begin{array}{l}\mathbf{2 6 , 5} \\
\%\end{array}$ & $3,5 \%$ & $\begin{array}{l}3,5 \\
\%\end{array}$ \\
\hline
\end{tabular}

El título de la Resolución A/RES/61/170 es: "Derechos humanos y medidas coercitivas unilaterales". El comportamiento de voto fue: Francia, en ésta Resolución, se expresó contra. De la misma manera lo hicieron 23 miembros de la Francofonía, es decir 35,5\%. El conjunto de los miembros de la ONU fue de 54 de 192, es decir 28 \%. Esto hace una diferencia de 7,5 puntos. Podemos entonces concluir que una cierta disciplina de voto se manifestó en esta Resolución aunque en proporciones limitadas. Esta conclusión es afirmada por el hecho que los votos "a favor" son menos numerosos en el campo de los francófonos (58 \%) que para la totalidad de la Estados miembros de la ONU: $68 \%$, es decir una diferencia de casi 10\%.

El título de la Resolución A/RES/61/166 es: "Promoción de un diálogo en materia de derechos humanos basado en la equidad y el respeto mutuos". Las conclusiones a las que llegamos para la Resolución anterior son aplicables para la presente Resolución. Sin embargo el "grupo de presión" francófono está menos marcado puesto que la diferencia entre el campo francófono que votó contra, en armonía con Francia, es superior sólo en 4 puntos al voto del conjunto de los miembros de la ONU.

El título de la Resolución A/RES/61/159 es: "Composición del personal de la oficina del alto comisionado de las Naciones Unidas para los derechos humanos". En esta Resolución, los efectos de un grupo de presión francófono son bastante evidentes, puesto que el grupo de 25 sobre 65 miembros de la OIF que observaron un comportamiento de voto en la misma dirección que el de Francia y que podría, de algún modo ser considerado "el campo de los fieles a Francia", en su abstención, representa un 38,5\% contra 55 sobre 192 para el conjunto de los 
Estados de la ONU que representa $29 \%$. Esto evidencia una diferencia de casi 10 puntos que se puede calificar de significativa. Un porcentaje que se encuentra casi en el voto opuesto a la elección de Francia a saber que el grupo francófono sólo votó "a favor" en un 52\% contra 61,5\% o sea una diferencia de 9 puntos.

El título de la Resolución A/RES/61/156 es: "la globalización y sus consecuencias para el pleno disfrute de todos los derechos humanos". Los resultados que observamos por lo que se refiere al voto de la Resolución 61/156 son totalmente comparables a los resultados de los votos de la Resolución 61/159.

El título de la Resolución A/RES/61/151 es: "Utilización de mercenarios como medio de violar los derechos humanos y obstaculizar el ejercicio del derecho de los pueblos a la libre determinación". Esta última Resolución de nuestra selección de 5 Resoluciones para el $61^{\circ}$ período de sesiones (2006/2007), evidencia resultados sensiblemente idénticos a los votos de la anterior Resolución y no conlleva, de nuestra parte, observación particular.

Se llegó a la conclusión parcial que: éstas, cinco Resoluciones ponen de manifiesto que existe efectivamente una convergencia de voto en una serie de miembros de la OIF que pertenecen a la ONU. Hemos, en efecto podido constatar que las elecciones de voto, cualquiera que éste sea (contra o abstención) de Francia implica, por parte de una serie de miembros de la OlF, comportamientos idénticos. Podemos pues, afirmar que existe la manifestación de un Poder blando, aunque éste sigue siendo parcial puesto que sólo se refiere a alrededor un $37 \%$ de los votantes para estas 5 Resoluciones.

\section{Votos del $60^{\circ}$ período de sesiones}

El cuadro 2, representa las Resoluciones votadas durante el 60 o período de Sesiones de la Asamblea General de las Naciones Unidas. Para dicho período, las resoluciones elegidas fueron A/RES/60/226, A/RES/60/184, A/RES/60/152, A/RES/60/143, A/RES/60/70.

\section{Cuadro 2: 60 período de sesiones (septiembre de 2005 a septiembre de 2006)}

\begin{tabular}{|c|c|c|c|c|c|c|c|c|c|c|c|}
\hline \multirow[b]{2}{*}{$\begin{array}{l}\text { RESOLUCIO } \\
\text { NES }\end{array}$} & \multirow[b]{2}{*}{$\begin{array}{l}\text { TITULO DE LA } \\
\text { RESOLUCION }\end{array}$} & \multicolumn{5}{|c|}{60 Estados de la Francofonía ${ }^{31}$} & \multicolumn{5}{|c|}{191 Estados de I'ONU } \\
\hline & & $\begin{array}{l}\text { Vot } \\
\text { os y } \\
\%\end{array}$ & $\begin{array}{l}\text { A } \\
\text { favo } \\
r\end{array}$ & $\begin{array}{l}\text { En } \\
\text { cont } \\
\text { ra }\end{array}$ & $\begin{array}{l}\text { Abst } \\
\text { enci } \\
\text { ón }\end{array}$ & $\begin{array}{l}\text { Aus } \\
\text { ente } \\
s\end{array}$ & $\begin{array}{l}\text { Vot } \\
\text { os } \\
y \%\end{array}$ & $\begin{array}{l}\text { A } \\
\text { favo } \\
r\end{array}$ & $\begin{array}{l}\text { En } \\
\text { cont } \\
\text { ra }\end{array}$ & $\begin{array}{l}\text { Abst } \\
\text { enci } \\
\text { ón }\end{array}$ & $\begin{array}{l}\text { Aus } \\
\text { ente } \\
s\end{array}$ \\
\hline \multirow[t]{2}{*}{$\begin{array}{l}\text { A/RES/60/ } \\
226\end{array}$} & \multirow[t]{2}{*}{$\begin{array}{l}\text { "Voto en } \\
\text { transparencia en } \\
\text { armamentos". }\end{array}$} & \#V & $\begin{array}{l}27 \\
\text { Fran } \\
\text { cia }\end{array}$ & 0 & 6 & 27 & \#V & 97 & 0 & 20 & 74 \\
\hline & & $\%$ & $45 \%$ & $0 \%$ & $10 \%$ & $45 \%$ & $\%$ & $\begin{array}{l}\mathbf{5 0 , 5} \\
\%\end{array}$ & $0 \%$ & $\begin{array}{l}10,5 \\
\%\end{array}$ & $39 \%$ \\
\hline
\end{tabular}




\begin{tabular}{|c|c|c|c|c|c|c|c|c|c|c|c|}
\hline \multirow[t]{2}{*}{$\begin{array}{l}\text { A/RES/60/ } \\
184\end{array}$} & \multirow[t]{2}{*}{$\begin{array}{l}\text { "Comercio } \\
\text { internacional y } \\
\text { desarrollo". }\end{array}$} & \#V & 29 & 0 & $\begin{array}{l}21 \\
\text { Fran } \\
\text { cia }\end{array}$ & 10 & $\# \mathbf{v}$ & 121 & 1 & 51 & 18 \\
\hline & & $\%$ & $48 \%$ & $0 \%$ & $35 \%$ & $\begin{array}{l}16,5 \\
\%\end{array}$ & $\%$ & $63 \%$ & $\begin{array}{l}0,5 \\
\%\end{array}$ & $\begin{array}{l}\mathbf{2 6 , 5} \\
\%\end{array}$ & $10 \%$ \\
\hline \multirow[t]{2}{*}{$\begin{array}{l}\text { A/RES/60/ } \\
152\end{array}$} & \multirow[t]{2}{*}{$\begin{array}{l}\text { "Impacto del } \\
\text { globalización en los } \\
\text { derechos humanos". }\end{array}$} & \#V & 32 & $\begin{array}{l}22 \\
\text { Fran } \\
\text { cia }\end{array}$ & 0 & 6 & \#V & 121 & 53 & 4 & 13 \\
\hline & & $\%$ & $\begin{array}{l}\mathbf{5 3 , 5} \\
\%\end{array}$ & $\begin{array}{l}36,5 \\
\%\end{array}$ & $0 \%$ & $10 \%$ & $\%$ & $63 \%$ & $28 \%$ & $2 \%$ & $7 \%$ \\
\hline \multirow[t]{2}{*}{$\begin{array}{l}\text { A/RES/60/ } \\
143\end{array}$} & \multirow{2}{*}{$\begin{array}{l}\text { "Inadmisibilidad de } \\
\text { ciertas practicas que } \\
\text { contribuyen a } \\
\text { exacerbar las formas } \\
\text { contemporáneas de } \\
\text { racismo, } \\
\text { discriminación racial, } \\
\text { xenofobia y formas } \\
\text { conexas de } \\
\text { intolerancia". }\end{array}$} & $\# \mathbf{V}$ & 27 & 0 & $\begin{array}{l}24 \\
\text { Fran } \\
\text { cia }\end{array}$ & 9 & $\# \mathbf{V}$ & 114 & 4 & 57 & 16 \\
\hline & & $\%$ & $45 \%$ & $0 \%$ & $40 \%$ & $15 \%$ & $\%$ & $\begin{array}{l}\mathbf{5 9 , 5} \\
\%\end{array}$ & $2 \%$ & $\begin{array}{l}29,5 \\
\%\end{array}$ & $9 \%$ \\
\hline \multirow[t]{2}{*}{$\begin{array}{l}\text { A/RES/60/ } \\
70\end{array}$} & \multirow[t]{2}{*}{ "Desarme nuclear". } & \#V & 31 & $\begin{array}{l}21 \\
\text { Fran } \\
\text { cia }\end{array}$ & 3 & 5 & \#V & 113 & 45 & 20 & 13 \\
\hline & & $\%$ & $\begin{array}{l}\mathbf{5 1 , 5} \\
\%\end{array}$ & $35 \%$ & $5 \%$ & $\begin{array}{l}\mathbf{8 , 5} \\
\%\end{array}$ & $\%$ & $59 \%$ & $\begin{array}{l}\mathbf{2 3 , 5} \\
\%\end{array}$ & $\begin{array}{l}10,5 \\
\%\end{array}$ & $7 \%$ \\
\hline
\end{tabular}

El título de la Resolución A/RES/60/226 es: "Voto en transparencia en armamentos". Un 45\% de los miembros de la OIF acompañaron a Francia en su voto para esta Resolución, y si se compara el resultado con el del conjunto de los miembros de la ONU (50,5\%) para esta Resolución, una primera conclusión se impone: la OIF se divide demasiado para haber podido ejercer, realmente, cualquier Poder blando en el voto relativo a esta Resolución (A/RES/60/226). La tentación sería de dar más explicaciones de las que ya se dieron. Aquí surgirían dos postulados opuestos. El primero trataría de preguntarse, por ejemplo, sobre la tasa de abstención en el voto. En este sentido podemos, constatar que ésta es más importante en el caso del grupo de los Estados miembros de la OIF que para el conjunto de los miembros de la ONU. Si admitimos que existe realmente una solidaridad - incluso parcial - de voto en el grupo 
de la OIF, una ausencia de la misma se ve reflejada en el hecho de expresarse contra pero sin mostrarlo... Hipótesis de nuestra parte, por supuesto. El segundo, y mirando este comportamiento desde otro punto de vista, veríamos que de los 60 miembros de la OIF 27 votaron con Francia (los del grupo que aquí hemos llamado G-Francia), sólo 6 lo hicieron mediante abstención, demarcando una posición de no acuerdo con este primer grupo mientras que 27 Estados más fueron registrados como ausentes. Esos Estados corresponden a aquellos que justamente nunca observan un comportamiento de voto en la misma dirección que el grupo Francia. ¿̇No podríamos acaso preguntarnos, por el contrario que en el postulado anterior, si no se trataría (hipótesis nuestra nuevamente) de justamente un comportamiento en el que no sentar una posición es no demostrar un consenso casi perfecto entre la posición de los Estados miembros de la OIF? La respuesta a esta pregunta sigue manteniéndose en los dominios de la mera especulación.

El título de la Resolución A/RES/60/184 es: "Comercio internacional y desarrollo". El grupo Francia de la OIF sólo cuenta un 35\% de los 60 miembros, lo que representa 21 países. Es algo menos que la media habitual, es decir algo menos de la media sobre estas 5 Resoluciones del $60^{\circ}$ periodo de sesiones que es de 38,5\%. Notemos igualmente, que de los miembros de la OIF sólo el $48 \%$ votó esta Resolución "a favor" contra el $63 \%$ del conjunto de los Estados de la ONU.

El título de la Resolución A/RES/60/152 es: "Impacto del globalización en loa derechos humanos". Sobre el voto de esta Resolución, podemos decir que el grupo Francia en la OIF obtiene un resultado un poco mejor que el anterior (Resolución 60/184), por una parte porque Francia agrupó un $36,5 \%$ de los votantes (contra, solamente $28 \%$ para el conjunto de los miembros de la ONU). Pero también porque los votantes "a favor" esta Resolución son, solamente del 53,5\% para el grupo OIF, contra un 63\% para el conjunto de los miembros de la ONU.

El título de la Resolución A/RES/60/143 es: "Inadmisibilidad de ciertas prácticas que contribuyen a exacerbar las formas contemporáneas de racismo, discriminación racial, xenofobia y formas conexas de intolerancia". En esta Resolución, podemos observar que el grupo Francia se abstuvo en una proporción bastante elevada con relación a los resultados medios de esta sesión 60 de la ONU: un 40\% contra 38,3\%. Esto es reforzado por el hecho de que sólo un $45 \%$ de los miembros del grupo OIF haya votado la Resolución "a favor", contra un $59,5 \%$ de los miembros de la ONU.

El título de la Resolución A/RES/60/70 es: "Desarme nuclear". Sobre esta cuestión del desarme nuclear, los resultados del grupo Francia de la OIF, son menos buenos (en el sentido que el Soft Power de la OIF parece ha funcionado menos bien) en términos relativos y sobre todo si lo 
comparamos (porcentualmente) con la participación en la misma dirección de los miembros de la ONU. En efecto, sólo un 35\% de los miembros de la OIF votaron con el grupo Francia. Esto es sin embargo, compensado, en parte, con el hecho de que los Estados miembros de la ONU votaron al 59 \% para esta Resolución. O sea 7,5 puntos más que para el grupo Francia de la OIF.

\subsection{Votos del $59^{\circ}$ período de sesiones}

El cuadro 3, representa las Resoluciones votadas durante el $59^{\circ}$ período de Sesiones de la Asamblea General de las Naciones Unidas. Para dicho período, las resoluciones elegidas fueron A/RES/59/280, A/RES/59/204, A/RES/59/193, A/RES/59/129, A/RES/59/77.

Cuadro 3: $59^{\circ}$ periodo de sesiones (de octubre de 2004 a septiembre de 2005)

\begin{tabular}{|c|c|c|c|c|c|c|c|c|c|c|c|}
\hline \multirow{2}{*}{$\begin{array}{l}\text { RESOLUCI } \\
\text { ONES }\end{array}$} & \multirow[b]{2}{*}{$\begin{array}{l}\text { TITULO DE LA } \\
\text { RESOLUCION }\end{array}$} & \multicolumn{5}{|c|}{60 Estados de la Francofonía } & \multicolumn{5}{|c|}{191 Estados de l'ONU } \\
\hline & & $\begin{array}{l}\text { Votos } \\
y \%\end{array}$ & $\begin{array}{l}\text { A } \\
\text { favo } \\
r\end{array}$ & $\begin{array}{l}\text { En } \\
\text { contr } \\
\text { a }\end{array}$ & $\begin{array}{l}\text { Abst } \\
\text { enci } \\
\text { ón }\end{array}$ & $\begin{array}{l}\text { Ause } \\
\text { ntes }\end{array}$ & $\begin{array}{l}\text { Vot } \\
\text { os } \\
y \%\end{array}$ & $\begin{array}{l}\text { A } \\
\text { favo } \\
\mathbf{r}\end{array}$ & $\begin{array}{l}\text { En } \\
\text { contr } \\
\text { a }\end{array}$ & $\begin{array}{l}\text { Abst } \\
\text { enci } \\
\text { ón }\end{array}$ & $\begin{array}{l}\text { Ause } \\
\text { ntes }\end{array}$ \\
\hline \multirow[t]{2}{*}{$\begin{array}{l}\text { A/RES/59 } \\
/ 280\end{array}$} & \multirow{2}{*}{$\begin{array}{l}\text { "Voto sobre la } \\
\text { declaración de la } \\
\text { clonación humana". }\end{array}$} & $\# \mathbf{V}$ & 9 & $\begin{array}{l}26 \\
\text { Fran } \\
\text { cia }\end{array}$ & 10 & 15 & \#V & 34 & 84 & 37 & 36 \\
\hline & & $\%$ & $15 \%$ & $43 \%$ & $17 \%$ & $25 \%$ & $\%$ & $18 \%$ & $44 \%$ & $19 \%$ & $19 \%$ \\
\hline \multirow[b]{2}{*}{$\begin{array}{l}\text { A/RES/59 } \\
/ 204\end{array}$} & \multirow[b]{2}{*}{$\begin{array}{l}\text { "Respeto de los } \\
\text { propósitos y principios } \\
\text { consagrados en la } \\
\text { carta de la Naciones } \\
\text { Unidas para lograr la } \\
\text { cooperación } \\
\text { internacional en la } \\
\text { promoción y el } \\
\text { estímulo del respeto } \\
\text { de los derechos } \\
\text { humanos y libertades } \\
\text { fundamentales en la } \\
\text { solución de los } \\
\text { problemas } \\
\text { internacionales de } \\
\text { carácter humanitario". }\end{array}$} & $\# \mathbf{V}$ & 34 & $\begin{array}{l}23 \\
\text { Fran } \\
\text { cia }\end{array}$ & 1 & 2 & \#V & 118 & 55 & 13 & 5 \\
\hline & & $\%$ & $\begin{array}{l}56,5 \\
\%\end{array}$ & $\begin{array}{l}38 \\
\%\end{array}$ & $2 \%$ & $4 \%$ & $\%$ & $62 \%$ & $29 \%$ & $7 \%$ & $2 \%$ \\
\hline
\end{tabular}




\begin{tabular}{|c|c|c|c|c|c|c|c|c|c|c|c|}
\hline \multirow[t]{2}{*}{$\begin{array}{l}\text { A/RES/59 } \\
/ 193\end{array}$} & \multirow[t]{2}{*}{$\begin{array}{l}\text { "Distribución } \\
\text { geográfica equitable" }\end{array}$} & \#V & 33 & $\begin{array}{l}23 \\
\text { Fran } \\
\text { cia }\end{array}$ & 1 & 3 & \#V & 128 & 52 & 4 & 7 \\
\hline & & $\%$ & $\begin{array}{l}55 \\
\%\end{array}$ & $\begin{array}{l}38 \\
\%\end{array}$ & $2 \%$ & $5 \%$ & $\%$ & $67 \%$ & $\mathbf{2 7} \%$ & $2 \%$ & $4 \%$ \\
\hline \multirow[t]{2}{*}{$\begin{array}{l}\text { A/RES/59 } \\
/ 129\end{array}$} & \multirow{2}{*}{$\begin{array}{l}\text { "Aplicación de la } \\
\text { declaración sobre la } \\
\text { concesión de la } \\
\text { independencia a los } \\
\text { países y pueblos } \\
\text { coloniales por los } \\
\text { organismos } \\
\text { especializados y las } \\
\text { instituciones } \\
\text { internacionales } \\
\text { relacionadas con las } \\
\text { Naciones Unidas". }\end{array}$} & \#V & 33 & 0 & $\begin{array}{l}24 \\
\text { Fran } \\
\text { cia }\end{array}$ & 3 & \#V & 121 & 0 & 57 & 13 \\
\hline & & $\%$ & $\begin{array}{l}55 \\
\%\end{array}$ & $0 \%$ & $\begin{array}{l}\mathbf{4 0} \\
\%\end{array}$ & $5 \%$ & $\%$ & $63 \%$ & $0 \%$ & $30 \%$ & $7 \%$ \\
\hline \multirow[t]{2}{*}{$\begin{array}{l}\text { A/RES/59 } \\
\text { /77 }\end{array}$} & \multirow[t]{2}{*}{ "Desarme nuclear". } & \#V & 30 & 0 & $\begin{array}{l}24 \\
\text { Fran } \\
\text { cia }\end{array}$ & 6 & \#V & 118 & 0 & 63 & 10 \\
\hline & & $\%$ & $\begin{array}{l}50 \\
\%\end{array}$ & $0 \%$ & $\begin{array}{l}40 \\
\%\end{array}$ & $10 \%$ & $\%$ & $62 \%$ & $0 \%$ & $33 \%$ & $5 \%$ \\
\hline
\end{tabular}

El título de la Resolución A/RES/59/280 es: "voto sobre la declaración de la clonación humana". La lectura del comportamiento de votación es muy diciente. En efecto, ninguna tendencia aparece como evidente. $O$ más bien, ningún grupo de presión francófono se manifiesta significativamente. Francia y el grupo de sus fieles, sólo está constituido por 26 de los 60 miembros que tienen representación en la ONU, lo que significa un $43 \%$ de los países de la OIF a haberse pronunciado contra esta Resolución. Si comparamos a esta cifra con la del conjunto de los miembros de la ONU, constatamos que estamos en el mismo orden de magnitud: $43 \%$, contra $44 \%$. Si consideramos, ahora, las cifras de "a favor", un $18 \%$ de los miembros de la ONU, contra solamente un 15\% para los países francófonos, o aún las "abstenciones" 19\% (miembros de la ONU) contra 17\% (miembros OIF), constatamos que el número de votos para esta Resolución (y en consecuencia contra el grupo de los francófonos conducidos en el grupo Francia) fue, relativamente menos desfavorable en los 60 miembros de la OIF que para el conjunto de países miembros de la ONU. Sin embargo la diferencia de 3 puntos (a favor) 4 
puntos (abstención) no puede permitirnos una interpretación definitiva. Ella es, en efecto, demasiado escasa para ser realmente significativa.

Es conveniente, sin embargo, proponer una reflexión que podría explicar estos resultados poco significativos en términos de tendencias. Ello podría deberse al tema de la Resolución. La clonación humana es un tópico que genera tantos defensores como detractores, convirtiéndose así en un tema altísimamente controversial. En efecto, la clonación humana plantea problemas éticos importantes por el antagonismo de las posiciones que acabamos de mencionar. Por un lado están los defensores de un recurso a la clonación de células humanas, en particular, los científicos y los médicos, como un medio de salvar vidas; por el otro están los defensores de unos valores morales estrictos que ven en estos métodos el riesgo de tergiversaciones de todas las clases. El tema es pues delicado. Se puede pensar que está incluido en la conciencia individual y por extrapolación en la conciencia de los Estados. Si ninguna tendencia aparece claramente esto se debe probablemente a la naturaleza del tema de la Resolución 59/280.

El título de la Resolución A/RES/59/204 es: "Respeto de los propósitos y principios consagrados en la carta de la Naciones Unidas para lograr la cooperación internacional en la promoción y el estímulo del respeto de los derechos humanos y libertades fundamentales en la solución de los problemas internacionales de carácter humanitario". De nuevo aparece en el resultado de los votos para la adopción de esta Resolución, la evidencia de un cierto grupo de presión de la OIF. El 38\% de los votos favorables a "contra" del grupo Francia se ajusta a la media de esta sesión (38,3\%). Tanto más que existe una diferencia de 11 puntos, entre el voto de los miembros de la OIF y el voto del conjunto de los miembros de la ONU (38\% contra 29\%). El título de la Resolución A/RES/59/193 es: "Distribución geográfica equitable". Los resultados de la votación de esta Resolución sobre la "distribución geográfica equitable" son relativamente idénticos a los de la Resolución 59/204. No generan, de nuestra parte, ninguna observación particular.

El título de la Resolución A/RES/59/129 es: "Aplicación de la declaración sobre la concesión de la independencia a los países y pueblos coloniales por los organismos especializados y las instituciones internacionales relacionadas con las Naciones Unidas". La misma observación que para la Resolución anterior.

El título de la Resolución A/RES/59/77 es: "Desarme nuclear". Esta Resolución, por el contrario de las dos anteriores permite evidenciar la existencia de un cierto Soft Power ejercido por el Grupo Francia. El resultado en favor de la abstención (40\%) es superior en unos 7 puntos a los votos de los miembros de la ONU (33\%). Además el voto "a favor" de los países de la OlF, es en un 12 puntos inferior al del conjunto de los Estados de la ONU. 
Como se pudo observar a lo largo de la lectura del comportamiento de voto de los miembros de la OIF en la Asamblea General de las Naciones Unidas para las quince Resoluciones estudiadas, se puede inferir que:

Primero, se podría decir que sí existe un cierto Soft Power de la OIF que se ejerce en la ONU en lo que se refiere al voto de las Resoluciones. Pero éste no tiene nada de masivo. En otros términos, los Estados miembros de la OIF no hacen frente común para votar "a favor" o "contra" 0 abstenerse con respecto a tal o cual Resolución.

Segundo, el tema de las Resoluciones interviene poco, al parecer, en los votos, salvo en el caso de la Resolución A/RES/59/77. En efecto, entre las quince Resoluciones analizadas podemos notar que la diferencia del número de votantes por el grupo Francia es poco significativa: puesto que es de 21 para el número más escaso y de 27 para el más elevado, pero que el promedio es 23 ó 24. Se podría avanzar la conclusión según la cual habría un "aspecto mecánico", sistemático que se encuentra en el proceso de voto. Hay que señalar que si bien es cierto que se puede identificar, en el seno de los Estados de la OIF, un Poder blando que se ejerce en favor de Francia y de sus fieles, también existe, por parte de otro grupo, igualmente dentro del seno de los 60 Estados francófonos, un Poder que se ejerce en oposición al grupo Francia.

Tercero, se puede afirmar que, incluso si se ejerce una disciplina de voto, cada Estado permanece soberano en su elección o no de votar una Resolución o abstenerse cualquiera que sea la elección, sobre este tema del grupo Francia y de sus principales adeptos.

Tengamos en cuenta, finalmente, que los Estados que no votan con el grupo Francia, prefieren, en general, la abstención o la no participación en el voto, más bien que votar contra Francia. Podemos también notar que la disciplina de voto raramente se contradice en el grupo del círculo limitado, y esto cualquiera que sea el tema de la Resolución pero que en el resto del grupo francófono, la libertad se impone como el principio general que sobresale ante cualquier otro valor.

Por otra parte, el estudio llevado a cabo en las líneas anteriores, permitió igualmente constatar que dentro de la nebulosa francofonía de la OIF, existían corrientes. El análisis "nominativo" que figura a continuación nos permite precisar lo que sólo era una impresión. En efecto, el estudio de los votos de cada uno de los miembros de la OIF (65 a partir de 2005/2006 - 60 en 20042005), es revelador de los comportamientos electorales sistemáticos. Para más legibilidad de nuestra reflexión procedimos a una reagrupación de los Estados en función de su mayor o menor "fidelidad" al grupo Francia. Esto nos permitió establecer la clasificación siguiente en función de la regularidad en los votos (a favor, en contra, abstención, o ausencia), con respecto a una Resolución en la Asamblea General de la $\mathrm{ONU}$ y en relación con la similitud al comportamiento 
de voto del Estado Francia en el mismo estamento. El estudio se refiere a las 15 Resoluciones analizadas.

Proponemos la siguiente nomenclatura dentro de la OIF:

Grupo 1. Siempre (o casi) de acuerdo con el voto francés. Al interior de este grupo de Estados miembros de la OIF, sólo contamos Países Europeos que corresponden al 38,5 \% del grupo (sin distinción: Europa Oriental y Europa Occidental). Tengamos en cuenta que ningún país en vía de desarrollo figura en él. En este grupo de fieles observamos un "núcleo" constituido de 6 países miembros plenos de la OIF: Austria, Bélgica, Bulgaria Francia, Luxemburgo, la República Checa. Estados observadores o Asociados, Chipre, Serbia y Ucrania han igualmente adoptado, una disciplina de voto absoluta, los tres votan cada vez las Resoluciones en el mismo sentido (con Francia y este grupo de 6 países).

Grupo 2. A veces de acuerdo con el voto francés. Es un grupo donde la libertad de voto es una prioridad. Este grupo es bastante heterogéneo. En él encontramos representantes europeos, africanos, asiáticos... Aquello que los acerca es que pertenecen al grupo de los países en vía de desarrollo, o por los menos de los países que no pertenecen al conjunto de las naciones más favorecidas y corresponde al $12.5 \%$ de los Estados miembros de la OIF.

Grupo 3. Nunca de acuerdo con el voto francés. Está constituido por países en desarrollo y representan el $49 \%$ del grupo.

Ante un comportamiento semejante, en el Soft Power observado en el voto de los Estados miembros de la OIF podría inferirse una cierta influencia de las relaciones internas de la OIF. Una de esas relaciones se da mediante la cooperación.

De hecho, además de su acción política, la OIF es una organización que tiene, como uno de sus objetivos la cooperación para el desarrollo de sus Estados miembros. A propósito, en los documentos constitutivos de la OIF tales como el "Marco decenal de desarrollo de la Francofonía"32" se afirma que "A partir de la Convención de Niamey, creando en 1970 la Agencia de cooperación cultural y técnica, los países signatarios han definido la Francofonía como la conciencia de la solidaridad que les une a través del uso de la lengua francesa y por el deseo de promover sus culturas sobre un pie de igualdad. ${ }^{\prime \prime 33}$ Un pie de igualdad que se busca alcanzar mediante la cooperación que trae consigo bienestar y desarrollo.

Un ejemplo de esto es la cooperación para el desarrollo de la prensa en los países miembros de la OIF. A este respecto, la OIF actúa desde dos frentes; es decir mediante dos tipos de programa: uno destinado a la prensa local privada y otro a la prensa local pública. En cuanto a la prensa 
privada existe un Fondo de apoyo a la prensa escrita del Sur que ofrece formaciones y transferencia de tecnología ${ }^{34}$ y busca dinamizar las redes teniendo en cuenta los principios básicos del periodismo de libertad de prensa, deontología y democracia. En cuanto a la prensa pública, la OIF adelanta un programa llamado de numerización de archivos gubernamentales del África ${ }^{35}$ francófona. A partir de 2007, se adelantará un Plan de modernización de las agencias de prensa públicas del África francófona (2007-2009), en miras a dar un nuevo soplo a las agencias de prensa africanas. La OIF también agencia una red de intercambios entre periodistas africanos, canadienses, asiáticos y europeos, llamada Syfia y una plataforma de intercambio de contenidos redaccionales entre periódicos del Sur llamada Médiaf. También tiene planes de apoyo a las radios locales y de ayuda a las televisiones del sur.

Otro ejemplo de cooperación es la del apoyo al desarrollo mediante el deporte. La OIF cuenta con una instancia intergubernamental de cooperación para el apoyo al deporte llamada Conféjes. El deporte se constituye de este modo en otra de las vías por las cuales pasa la difusión del Soft Power de la OIF. Esta instancia busca incentivar la práctica masiva del mismo, apoyar acciones de desarrollo del deporte de alto nivel, contribuir a una participación equilibrada de mujeres adultas y jóvenes a las actividades de la juventud y del deporte, contribuir a una mejor integración por el deporte de las personas discapacitadas ${ }^{36}$.

Todos los objetivos aquí reseñados se inscriben en una dinámica de difusión del Soft Power de la OIF. Apoyar acciones contra el dopaje es, además de insertarse en lucha por la salud pública de los jóvenes del mundo, una manera de demostrar que la Organización trabaja en concordancia con los valores que el mundo moderno persigue; es una forma de reforzar su Soft Power en instancias alternativas que lo ayudan a difundirse. Recordemos que NYE sostiene que una de las características de este tipo de poder es justamente la de ser poder difuso.

Un tercer ejemplo es el de la cooperación educativa. A propósito, en 1989, durante la $3^{a}$ Cumbre en Dakar (Senegal) fueron reconocidos como ejes de cooperación privilegiados: la educación y la formación (como primero de ellos), el medio ambiente, como segundo y finalmente el de la democracia y el estado de derecho ${ }^{37}$. Es clara la importancia que el tema de la cooperación educativa y de la formación va tomando en la medida que evoluciona el sistema francófono para convertirse en una Organización Internacional. Además, en 2002 se generaron compromisos para la cooperación al desarrollo educativo al interior de la OIF. Estos compromisos fueron renovados en 2004 durante la 10 Cumbre. Hoy en día, la OIF cuenta con operadores del tipo de la Agencia Universitaria de la Francofonía (AUF), la Universidad Senghor de Alejandría y la Asociación Internacional de Alcaldes y Responsables de las capitales y de la metrópolis parcialmente o enteramente francófonas (AIMF). Todos ellos tienen una misión manifiesta y una misión intrínseca. Su misión manifiesta es la de ser los ejecutores de la política de cooperación educativa de la OIF. La misión intrínseca por su parte es la de ejercer un tipo de 
tercera dimensión de diplomacia pública según los términos de NYE. La tercera dimensión de diplomacia pública consiste en el desarrollo de relaciones con individuos clave sobre varios años mediante estudiantes, intercambios, seminarios, conferencias, y acceso a los medios ${ }^{38}$. En las palabras del autor: ésta juega un importante papel en la creación de una imagen atractiva (de la organización) y que de ese modo conseguirá lo que busca: posicionamiento ${ }^{39}$ como un actor internacional en pro de la defensa de las causas culturales. Aquí se verifica un postulado determinante: "nuestra cultura se exporta en las mentes de quienes son formados por nosotros". La cooperación cultural y educativa brilla entonces por su importancia en términos de la difusión del Soft Power de la OIF.

Adicionalmente, la OIF trabaja en conjunto con la Organización de las Naciones Unidas para la Educación, la Ciencia y la Cultura (UNESCO), en asuntos de cooperación al desarrollo de países africanos particularmente. Estas dos organizaciones han trabajado mancomunadamente en proyectos de cooperación educativa interinstitucional como: el apoyo al programa Educación para Todos (EPT) de la UNESCO, y el Foro Regional "Dakar + 5" cuyo interés tuvo que ver con una revisión de los logros, en términos de educación universal en 2015 (en los países africanos particularmente) y el cómo conseguir una aceleración en su alcance.

Pero el Soft Power de la francofonía no se refuerza sólo mediante cooperación multilateral. La Cooperación bilateral es igualmente un importante vector de fortalecimiento de este poder.

\subsection{La cooperación bilateral francesa.}

La cooperación bilateral francesa tiene dos componentes. Un componente político definido por el poder central (Gobierno francés y Ministerio de Asuntos Exteriores y Europeos) y unos servicios que se encargan de aplicarla: Servicio de Cooperación y de Acción Cultural (SCAC) de la Embajada de Francia en Colombia especialmente. Junto con dicho servicio, los Liceos Franceses de Colombia (Louis-Pasteur de Bogotá, Paul Valery de Cali y Liceo Francés de Pereira) así como la Alianza Francesa presente en once ciudades el país, juegan, a títulos diversos, papeles de relevo de la cooperación bilateral francesa. Ellos juegan igualmente, de manera plena, el rol de difusores de la francofonía.

A fin de trascender los pares clásicos, subjetivismo/objetivismo, micro/macro, libertad/determinismo - que dominan cuando se asume el reto de rendir cuenta de un área, para el caso el de la cooperación bilateral y que dificultan la lectura, hemos elegido deliberadamente simplificar lo real, eligiendo una aproximación sociológica.

Es a Pierre BOURDIEU a quien debemos el material conceptual. Así, antes que de área hablaremos de campo, aquel de la cooperación bilateral que tiene por uno de sus vectores la 
francofonía. Este campo está poblado de actores, que ellos sean individuos (Embajador, Consejero Cultural, Agregado Cultural, de cooperación para el francés, para la cooperación universitaria, para los aspectos científicos y técnicos...) o bien que ellos sean instituciones (SCAC, Misión económica, liceos franceses, Alianza Francesa). En fin al interior del campo, los actores que ellos sean individuos o instituciones, se disputan unos bienes simbólicos y/o materiales $^{40}$.

La cooperación internacional entre Francia y Colombia está regida más directamente por dos actores institucionales mayores de la Embajada de Francia en Colombia: el Servicio de Cooperación y de Acción Cultural (SCAC) y a su manera la Misión Económica. El SCAC tiene por vocación: no solamente la difusión de la lengua y la cultura francesas sino también llevar a cabo acciones puntuales a mediano y largo plazo. El eje mayor de esta cooperación se titula: Cooperación para el desarrollo ${ }^{41}$. En cuanto a la Misión Económica: "Ella agrupa los servicios de la Dirección General del Tesoro y de la Política Económica (DGTPE). Los agregados fiscales y de aduanas laborando en el extranjero y también los consejeros y agregados financieros están igualmente integrados en los Servicios Económicos, dentro del marco de sus funciones específicas" $^{42}$. Sus misiones son de tres órdenes. Primero: "Analizar la situación económica y financiera del país considerado, tanto como las condiciones de acceso al mercado, en beneficio de la administración francesa y de las empresas. Participar en la implantación de una cooperación financiera entre Francia y el país de residencia". Segundo: "Apoyar los esfuerzos comerciales de las empresas exportadoras francesas, y de aquellas que están ya implantadas localmente. Participar en la promoción de las inversiones francesas en el país de residencia. Informar los industriales y las administraciones locales sobre la oferta francesa y, en asocio con la Agencia francesa para las Inversiones Internacionales (AFII), promover a Francia como lugar de acogida de las inversiones directas extranjeras". Tercero: "Contribuir, mediante un trabajo de recopilación y análisis de la información, en la definición de las propuestas de Francia y de la Unión Europea en el seno de los organismos multilaterales. Los Servicios Económicos son igualmente el portavoz, en sus respectivos países donde se encuentran, de la posición francesa en materia financiera y comercial, dentro del marco comunitario, regional o multilateral ${ }^{\prime \prime 3}$. Esta lectura, un poco más extensa de estas misiones, es sin embargo interesante. En efecto, esta muestra que este agente (la Misión Económica) tiene por vocación la de facilitar la implantación de la presencia económica y europea en Colombia.

Esta rápida presentación del SCAC y de la Misión Económica de la Embajada de Francia, si se pone en la perspectiva del concepto de Soft Power de NYE aplicado a la francofonía no carece de interés, ya que ella permite observar diferencias notorias de los roles respectivos que juegan dichos actores. Antes de intentar rendir cuenta de dichos roles, recordemos nuestro postulado: la francofonía está revestida de un Soft Power que profundiza por medio de cooperación. Nuestro objetivo aquí es el de verificarlo mediante el estudio de los efectos de la cooperación bilateral. 
Primero que todo el SCAC, por las acciones que él lleva a cabo en Colombia, se define claramente como un actor institucional de la francofonía. Este propone becas de estudios en Francia, desarrollo acciones de cooperación interuniversitaria (universidades francesas y colombianas), organiza pasantías para la formación continuada de profesores de francés, por ejemplo. Él está igualmente asociado, por medio de proyectos específicos a la Asociación COLombiana de PROfesores de Francés (ACOLPROF)... Pero lo verdaderamente relevante de saber esto es observar ¿̇cómo se puede identificar el Soft Power a través de estas acciones de cooperación?

Estas acciones tienen consecuencias evidentes sobre los comportamientos sociales y culturales de los actores colombianos que habrán beneficiado de ellas a un título u otro.

Tomemos el ejemplo de un estudiante que haya pasado varios años en Francia, preparando un Doctorado o siguiendo una formación en la escuela de ciencias políticas Sciences $\mathrm{Po}^{44}$., gracias a una beca. A su retorno a Colombia, regresará convertido (voluntariamente o no) en un actor de la francofonía a través del francés que él manejará perfectamente, a través de la cultura en la cual se reconocerá. ¿Cuáles serán sus referentes, en términos de funcionamiento profesional? Aquellos que él mismo habrá descubierto en Francia. ¿Quiénes serán sus contactos profesionales? Aquellos que se establecieron en el país receptor. Si hay hijos, éstos serán invitados a aprender el francés por lo menos, y/o a seguir sus estudios en un Liceo Francés de Colombia. Él mismo integrará el prestigioso Club Concorde ${ }^{45}$, que agrupa una gran parte de los ex-becarios del Gobierno francés.

Imaginemos ahora que el dicho estudiante de Sciences Po. se convierta en un actor de la vida política colombiana (esto no sería sorprendente, en vista del tipo de formación), ¿̇con qué país elegiría él establecer vínculos privilegiados de tener la posibilidad de hacerlo? La respuesta está naturalmente contenida en la pregunta.

Consideremos ahora la Alianza Francesa (AF). Notemos, que ella no es un servicio de la Embajada de Francia. Por el contrario, es una Asociación independiente cuya sede principal se sitúa en París y que está representada en el mundo entero. En Colombia, tal y como en todos los otros países del mundo en donde hace presencia, es de naturaleza local. Esto quiere decir se rige por la legislación nacional de cada país. Sin embargo, y como su misión es la de difundir la lengua y la cultura francesas, históricamente ha tenido vínculos estrechos con el Servicio Cultural de la Embajada de Francia. Pero en los últimos años se ha dado poco a poco, una transferencia parcial de la misión puramente cultural del SCAC hacia esta institución, que desde 2004 se convirtió en una Délégation Générale, ganando en autonomía.

La Alianza Francesa es, por definición un Agente de la francofonía. En efecto, además de los cursos de lenguas que ella dispensa, forma profesores de francés y propone a un público numeroso, actividades culturales de todo tipo. Los miles de estudiantes formados a la lengua y a 
la cultura francesas, convertidos ellos mismos actores de la francofonía, jugarán en este campo, un rol mayor de difusores y de amplificadores de la realidad francófona. A este título, ellos ejercerán un Soft Power que podría calificarse de "de terreno".

Los liceos franceses. En sus orígenes fueron creados para permitir a los hijos de los franceses en el extranjero, tener una escolaridad en todo aspecto, idéntica a aquella propuesta en Francia. Por la calidad de su nivel pedagógico, se convirtieron en una elección posible para las familias colombianas, a menudo ellas mismas francófonas y francófilas. Esta transformación contribuye ampliamente a favorecer un Soft Power de la francofonía. En efecto, algunos de dichos estudiantes colombianos, parten a Francia para realizar sus estudios superiores.

Abordemos ahora el papel de la Misión Económica y preguntémonos żsi ella juega un rol en el dicho Soft Power de la francofonía? y de ser así, ¿̇de qué manera se da esto? Este servicio, tal y como es presentado por la Embajada misma ${ }^{46}$, no tiene por vocación la de ser un agente institucional de la cooperación, sino un facilitador para la empresas francesas que buscan comerciar con Colombia. Esta Misión, pone en contacto ciertos agentes económicos de cada país mediante misiones, simposios y encuentros diversos. Esta puesta en contacto de los tejidos económicos porosos favorece las interacciones, ya sean estas de tipo profesional, cultural o lingüístico. Así, sin incluso saberlo, la Misión Económica juega un rol de difusor de la francofonía y por la misma ocasión permite desarrollar un Soft Power en beneficio de las empresas francesas y europeas.

Que esto tenga lugar directa o indirectamente, consciente o inconscientemente, estos actores de la francofonía, por lo que son y lo que hacen, practican un Soft Power. ¿Cómo? Simplemente, por la dinamización del campo. Expliquémonos. Louis PORCHER designa los individuos que están contenidos en un campo (aquí el de la francofonía) con el nombre de actores ${ }^{47}$. Un actor es aquel que actúa, o si se prefiere es un individuo en acción. Evolucionando en el campo de la francofonía, este actor va a intentar obtener bienes, de tipo simbólico o material. El hecho de querer obtener tales bienes va naturalmente, a dinamizar este campo, hacer nacer interacciones, crear redes, y áreas de influencia. Todas estas serían condiciones constitutivas de un Soft Power.

¿Cuáles son estos bienes, que ellos sean simbólicos o materiales? Los bienes simbólicos son aquellos que son sinónimo de prestigio, de reconocimiento. Para un profesor de lenguas publicar un artículo de didáctica en una revista prestigiosa no significa nada en términos financieros, pero contribuye a su notoriedad. Lo mismo sucede con un estudiante o un profesor que es admitido en el Club Concorde. Para un actor institucional, un colegio bilingüe por ejemplo, un bien simbólico importante es recibir la visita de un alto funcionario de la Embajada de Francia, con ocasión de las graduaciones al final del año escolar. 
Al lado de estos bienes simbólicos tenemos los bienes materiales cuyos ejemplos no faltan. Es por ejemplo, para un individuo, obtener una beca, recibir un subsidio del SCAC para una publicación, para un académico o una persona de renombre, es el ser invitado a Francia para un coloquio. Para un actor institucional es recibir una dotación en material o en dinero. A un título u otro, dichos actores, individuos o instituciones se convierten en beneficiarios de un sistema al que profesan reconocimiento, porque han obtenido un beneficio a cambio de su sumisión al campo. En un principio, beneficiarios de la prodigalidad de campo en cuestión y a menudo pasivos al inicio, se mutan en actores que defienden sus posiciones al interior del campo. Pero defendiendo sus posiciones personales, defienden a aquellas de la francofonía. Es así como se instaura naturalemente un Soft Power de la francofonía.

\section{Conclusiones}

A manera de conclusión hemos de decir que el estudio llevado a cabo sobre los votos de las Resoluciones en la Asamblea General de las Naciones Unidas, lo hemos visto, que un verdadero Soft Power de la francofonía institucional no es fácilmente verificable. La constatación que podemos hacer hoy, y que se apoya sobre un análisis del campo de la francofonía in situ es indiscutible. Creando dependencias, por la tentación de adquisición de bienes simbólicos y materiales, la cooperación Norte-sur genera un Soft Power, que no está regido por ninguna norma formulada pero cuyos efectos son considerables.

Es tentador, evidentemente, a fin de confirmar la afirmación precedente, tomar como ejemplo dichos países, ex-colonias francesas, que cerca de 50 años después de su independencia, han mantenido relaciones estrechas con el continente, no solamente en términos políticos sino igualmente económicos y culturales. Y lo que es cierto para el área de la francofonía lo es igualmente para aquel del Commonwealth, o de la zona de influencia de España en América Latina.

La lectura de los hechos no deja espacio a equivocación. El actor mayor de la francofonía, la OIF, cuando ella actúa como representante oficial del área francófona en la escena internacional, especialmente en la $\mathrm{ONU}$, no parece estar en la medida de ejercer un verdadero Soft Power. Contrariamente, a través de las acciones de cooperación que ella lleva a cabo y que benefician a sus miembros, se ejerce un Soft Power totalmente comparable a aquel que puede ser constatado en la cooperación bilateral franco-colombiana por ejemplo. 


\section{Referencias Bibliográficas}

Gomez Galan Manuel, SANAHUJA PERALES José Antonio. 1999 El sistema Internacional de Cooperación al desarrollo. Madrid. CIDEAL.

NYE, Joseph, Prymacy or World Order. Nueva York: McGraw-Hill. 1978.

NYE, Joseph, Soft power. 2004 The means to success in World Politics, Public Affairs, New York,

NYE Jr., Joseph, La paradoja del poder norteamericano. 2002 Taurus, Bogotá.

PORCHER Louis, 1987Champs de Signes, Etat de la Diffusion du Français Langue Etrangère. Didier / C.R.E.D.I.F., Paris.

WEBER Max, WINCKELMANN Johannes, 1987 Economía y Sociedad: esbozo de sociología comprensiva, capítulo 1. México, D.F. Fondo de cultura económica. FCE. México.

PARRA Andrea. 1987 La Francofonía Institucional ¿̇ Una manifestación del Soft Power?. Tesis de Magister en Análisis de problemas políticos, económicos e internacionales contemporáneos. Universidad Externado de Colombia/Institut des Hautes Etudes pour l'Amérique Latine (IHEAL) - Université Paris III. Agosto.

NYE Jr. Joseph S 2003 "Propaganda Isn't the Way: Soft Power", The International Herald Tribune, Enero 10

BROCOS FERNÁNDEZ José. 2009Soft Power" como estrategia de dominio e imposición cultural". en Revista Arbil n.100, es editado por el Foro Arbil, Zaragoza (España), Online. Disponible en < http://www.arbil.org/100broco.htm> ISSN: 1697-1389. Consultado el 10 de febrero

MOLINA David e IGLESIAS Marcela, "Poder e ideas: el papel de los think tanks en el diseño y ejecución de la política exterior estadounidense.", en 10 Revista Electrónica de Estudios Internacionales. Disponible en

http://www.reei.org/reei\%2010/D.Molina\&M.lglesias(reei 10).pdf. Consultado 8 de marzo de 2009. 
NYE Joseph, "The Benefits of Soft Power", en Harvard Business School Working Knowledge for Business Leaders. $8 / 2$ /2004. Disponible en

http://hbswk.hbs.edu/archive/4290.html. Consultado el 3 de marzo de 2009.

NYE Joseph, "Think Again: Soft Power", en Foreign Policy, 2006, disponible en http://yaleglobal.yale.edu/display.article?id=7059. Consultado febrero 2 de 2009.

\section{Sitios oficiales consultados}

AGENCIA UNIVERSITARIA DE LA FRANCOFONIA. Disponible en http://www.auf.org/. Consultado el 13 de marzo de 2009.

EMBAJADA DE FRANCIA EN COLOMBIA. Disponible en www.ambafrance-co.org. Consultado de 13 de marzo de 2009.

MINISTERIO DE ASUNTOS EXTERIORES Y EUROPEOS. Disponible en http://www.diplomatie.gouv.fr/es/ministerio-asuntos-exteriores-yeuropeos_197/index.html. Consultado el 13 de marzo de 2009.

ORGANIZACIÓN INTERNACIONAL DE LA FRANCOFONÍA. Ver http://www.francophonie.org/. Consultado el 12 de marzo de 2009.

ORGANIZACION DE LAS NACIONES UNIDAS. "Sesiones de la Asamblea General". Disponible en http://www.un.org/spanish/aboutun/organs/ga/61/. Consultado el 12 de marzo de 2009.

SCIENCES PO - Paris. Disponible en www.sciences-po.fr. Consultado el 13 de marzo de 2009. 
' Habitualmente traducido como poder blando.

${ }^{2}$ En el sentido sociológico del término que fuera propuesto por Pierre BOURDIEU.

${ }^{3}$ Jacques LEYLAVERGNE fue Agregado de Cooperación para el Francés en la Embajada de Francia durante el período correspondiente a 2001-2005.

${ }^{4}$ Joseph NYE, Jr. quien era en 2005 decano de la Kennedy School of Government de la Universidad de Harvard, ha trabajado en tres agencias gubernamentales: de 1977 a 1979 como Diputado para la Subsecretaría de Estado para la Asistencia de Seguridad, Ciencia y Tecnología y como Presidente del Grupo de No Proliferación de armas nucleares del Consejo Nacional de Seguridad. En 1993 y 1994 fue presidente del Consejo Nacional de Inteligencia. En 1994 y 1995 sirvió como Secretario Adjunto de Defensa para asuntos de seguridad internacional. Extraído de MOLINA David e IGLESIAS Marcela, "Poder e ideas: el papel de los think tanks en el diseño y ejecución de la política exterior estadounidense", en 10 Revista Electrónica de Estudios Internacionales, 2005, Disponible en http://www.reei.org/reei\%2010/D.Molina\&M.Iglesias(reei 10).pdf. Consultado 8 de marzo de 2009.

${ }^{5}$ ORGANIZACIÓN INTERNACIONAL DE LA FRANCOFONÍA. Ver http://www.francophonie.org/.

Consultado el 12 de marzo de 2009.

- MINISTERIO DE ASUNTOS EXTERIORES Y EUROPEOS. Disponible en http://www.diplomatie.gouv.fr/es/ministerio-asuntos-exteriores-y-europeos_197/index.html. Consultado el 13 de marzo de 2009.

${ }^{7}$ AGENCIA UNIVERSITARIA DE LA FRANCOFONIA. Disponible en http://www.auf.org/. Consultado el 13 de marzo de 2009.

${ }^{8}$ ORGANIZACION DE LAS NACIONES UNIDAS. "Sesiones de la Asamblea General". Disponible en http://www.un.org/spanish/aboutun/organs/ga/61/. Consultado el 12 de marzo de 2009.

9 NYE Joseph, "Think Again: Soft Power", en Foreign Policy. 2006. Disponible en http://yaleglobal.yale.edu/display.article?id=7059. Consultado febrero 2 de 2009.

${ }^{10}$ NYE Joseph, Prymacy or World Order, Nueva York, McGraw-Hill, 1978, p. 119

"Se han mantenido los términos Hard y Soft power en su idioma original (inglés) de manera deliberada. Traducciones exactas del término podrían ser poder duro y poder blando pero los autores de este artículo han elegido los términos en inglés.

${ }^{12}$ WEBER Max, WINCKELMANN Johannes, Economía y Sociedad: esbozo de sociología comprensiva, capítulo 7 , México D.F, Fondo de cultura económica, 1987, pp. 16.

${ }^{13}$ Idem NYE Joseph, Think Again... consultado el 2 de Marzo de 2009.

${ }^{14}$ Idem NYE Joseph, Prymacy..., p. 119.

${ }^{15}$ Idem, NYE Joseph, Prymacy..., p. 119

${ }^{16}$ NYE Joseph, "The Benefits of Soft Power", en Harvard Business School Working Knowledge for Business Leaders, 8 de febrero de 2004, p. 1.

${ }^{17}$ BROCOS FERNÁNDEZ José., "Soft Power como estrategia de dominio e imposición cultural", en Revista Arbil n. 100, edit. por el Foro Arbil, Zaragoza (España), Online. Disponible en < http://www.arbil.org/100broco.htm> ISSN: 1697-1389. Consultado el 10 de febrero de 2009.

${ }^{18}$ En esta cita se ha cambiado deliberadamente el término Estado que aparece en la versión original del trabajo de NYE basados en una investigación anterior denominada "La Francofonía institucional: ¿̇Una forma de poder blando? que demostró que también sería posible hablar de poder blando desde la perspectiva de otros actores internacionales diferentes a los Estados. Para efectos de la cita, ésta fue extraída de NYE, Joseph, Soft power. The means to success in World Politics, Public Affairs, New York, 2004, p. 2.

${ }^{19}$ Idem. p. 3.

${ }^{20}$ lbid p. 11. 
${ }^{21}$ PARRA Andrea. "La Francofonia Institucional: ¿̇Una Forma De Poder Blando?". Tesis de Magister en Análisis de problemas políticos, económicos e internacionales contemporáneos. Agosto de 2007. P. 53.

${ }^{22}$ NYE Joseph, La paradoja del poder norteamericano, Taurus, Bogotá, 2002, p. 31.

${ }^{23}$ lbid p. 32.

${ }^{24}$ NYE Joseph, La paradoja... p94

${ }^{25}$ NYE Joseph, "Propaganda Isn't the Way: Soft Power", en The International Herald Tribune, Enero 10 de 2003.

${ }^{26}$ NYE Joseph, "Soft power, the means...", p. 13.

${ }^{27}$ Esta sesión $61^{\circ}$ corresponde al período comprendido entre el 19 de septiembre de 2006 y septiembre de 2007.

${ }^{28}$ La sesión $60^{a}$ corresponde al período 2005/2006 y va del 16 de septiembre de 2005 al 8 de septiembre de 2006.

${ }^{29}$ La sesión $59^{\circ}$ corresponde al período 2004/2005 y va del 11 de octubre de 2004 al 13 de septiembre de 2005.

${ }^{30} \mathrm{El}$ grupo que constituye la Francofonía en el seno de la ONU durante este $61^{\circ}$ periodo de sesiones aumentó con ocasión de la Cumbre de Bucarest en octubre de 2006 (todos los estatus reunidos: miembros llamados de pleno derecho, miembros asociados y miembros observadores) de 60 a 65 miembros. El número real de todos los miembros actuales de la Francofonía es 68. Sin embargo, dentro de este grupo existen tres (Canadá - Québec, Canadá - New Brunswick y la Comunidad francófona de Bélgica por no ser Estados en sí mismos no tienen representación en la ONU y por lo tanto no tienen voto. Esta es la razón de soporte de la afirmación."65 miembros" en el cuerpo de este documento.

${ }^{31}$ El grupo que constituye la Francofonía en el seno de la ONU en este $60^{\circ}$ periodo de sesiones $(2005-2006)$ es el mismo que los constituyó durante el periodo $60^{\circ}$ (2004 - 2005). Este grupo había, de hecho, sido constituido durante la cumbre de la Francofonía en Ouagadougou (Burkina Faso) en 2004. Si el grupo cuenta un total de 63 miembros: 53 que son miembros plenos y 10 con estatus de Estados observadores, sólo 60 pertenecen a la ONU (de los 191 con que cuenta esta organización en este momento). No pueden, en efecto, formar parte: el Canadá Nuevo Brunswick, Quebec y la Comunidad francófona de Bélgica que no son Estados. Las cumbres de la OIF tienen lugar cada dos años y en consecuencia el número de miembros de la OIF (pleno derecho, observadores o asociados) no varía durante dos años. El número de representantes de la OIF en el $60^{\circ}$ periodo de sesiones es pues el mismo que en el $59^{\circ}$ periodo: 60.

${ }^{32}$ ORGANIZACIÓN INTERNACIONAL DE LA FRANCOFONIA-OIF http://www.francophonie.org/. Consultado marzo 7 de 2009.

${ }^{33}$ GOMEZ GALAN Manuel, SANAHUJA PERALES José Antonio. El sistema Internacional de Cooperación al desarrollo. Madrid. CIDEAL. 1999, p. 17.

${ }^{34}$ Aquí se trata de asistencia técnica, que por definición "pretende facilitar habilidades y capacidades técnicas y de gestión creando así una capacidad propia en el país receptor para gestionar su desarrollo. Dentro de la Asistencia técnica se encuentran actividades diversas de asesoría capacitación y apoyo institucional a menudo llevadas a cabo por expertos de los países donantes, de las organizaciones o de otros países en desarrollo más avanzados. En este campo son frecuentes las actividades de capacitación y de transferencia de tecnología y de Know-how para mejorar la eficiencia del tejido productivo. Idem, GOMEZ GALAN, p. 28.

${ }^{35}$ Idem OIF, Consultado marzo 7 de 2009.

${ }^{36}$ lbid. OIF, Consultado el 13 de marzo de 2009.

${ }^{37}$ Ibid. "Chronologie", en OIF, p. 4.

${ }^{38}$ NYE Joseph, Soft Power, The means to success in World Politics, Public Affairs, New York, 2004, pp. 108 - 109

${ }^{39}$ Idem, p. 110.

${ }^{40}$ BOURDIEU Pierre en PORCHER Louis, Champs de Signes, Etat de la Diffusion du Français Langue Etrangère, Didier / C.R.E.D.I.F., Paris, 1987, p. 12. 
${ }^{41}$ EMBAJADA DE FRANCIA EN COLOMBIA: "Francia adoptó los 8 objetivos del milenio para el desarrollo de la ONU (sept.2000). Según esos principios el SCAC apoya: La educación básica, La integración de los principios del desarrollo sostenible La democracia, el Estado de derecho y la modernización administrativa à través de : la democracia, el Estado de derecho y la modernización administrativa à través de : Encuentros jurídicos colombofranceses entre las cortes constitucionales y consejos de Estado; Capacitación de jueces, policías, ejecutivos administrativos de la función pública nacional o municipal, cooperación descentralizada entre municipios o gobernaciones, Estadías o estudios en Francia, à través del Instituto colombo- francés de altos Estudios para el Desarrollo (IHED) o de la Escuela Nacional de Administración (ENA)". Disponible en www.ambafrance-co.org. Consultado de 13 de marzo de 2009.

${ }^{42}$ Para completar esta información, referirse a la página web de la Embajada de Francia en el site: http://www.ambafrance-co.org/spip.php?article297\#Que-es-una-mision-economica.

${ }^{43}$ Idem.

${ }^{44}$ SCIENCES PO - Paris. Disponible en www.sciences-po.fr. Consultado el 13 de marzo de 2009.

${ }^{45}$ lbid. EMBAJADA DE FRANCIA...Disponible en http://www.ambafrance-co.org/spip.php? article1471, consultado 14 de marzo de 2009.

${ }^{46}$ Ibid. EMBAJADA DE FRANCIA... Disponible en http://www.ambafrance-co.org/spip.php?article297, consultado el 14 de marzo de 2009.

${ }^{47}$ Idem. PORCHER. 